\title{
Creative mood swings: divergent and convergent thinking affect mood in opposite ways
}

\author{
Soghra Akbari Chermahini · Bernhard Hommel
}

Received: 18 April 2011/ Accepted: 10 June 2011/Published online: 22 June 2011

(C) The Author(s) 2011. This article is published with open access at Springerlink.com

\begin{abstract}
Increasing evidence suggests that emotions affect cognitive processes. Recent approaches have also considered the opposite: that cognitive processes might affect people's mood. Here we show that performing and, to a lesser degree, preparing for a creative thinking task induce systematic mood swings: Divergent thinking led to a more positive mood, whereas convergent thinking had the opposite effect. This pattern suggests that thought processes and mood are systematically related but the type of relationship is process-specific.
\end{abstract}

\section{Introduction}

In contrast to the commonsense concept of affect and reason as antagonistic factors that compete for the control of our thoughts and actions, recent research has revealed evidence for numerous types of fruitful cooperation between affective and cognitive processes. For instance, positive mood and affect have been shown to facilitate associative (Bar, 2009) and semantic priming (Hanze \& Hesse, 1993), to enhance the recall of happy memories (Teasdale \& Fogarty, 1979), and to support the processing of global perceptual information (Gasper \& Clore, 2002); whereas negative mood and affect have been found to narrow the focus of attention (Rowe, Hirsh, \& Anderson,

S. Akbari Chermahini · B. Hommel

Cognitive Psychology Unit and Leiden Institute for Brain and

Cognition, Leiden University, Leiden, The Netherlands

B. Hommel $(\bowtie)$

Department of Psychology, Cognitive Psychology Unit,

Leiden University, Wassenaarseweg 52, 2333 AK Leiden,

The Netherlands

e-mail: hommel@fsw.leidenuniv.nl
2007), facilitating analytical processing, causal reasoning, and reliance on systematic processing (Pham, 2007), and to support forgetting (MacLeod, 2002; Bäuml \& Kuhbandner, 2009). A particularly close relationship seems to exist between mood and creative thinking. Various authors have assumed that positive mood enhances creativity (e.g., Isen, 1999; Hirt, Melton, McDonald, \& Harackiewicz, 1996), and numerous findings are consistent with this idea (for reviews, see Baas, De Dreu, \& Nijstad, 2008; Davis, 2009). At the same time, however, the type and nature of this interaction are not well understood and mediating factors like type of task (Davis, 2009), motivational set (Baas et al., 2008), and individual differences (Akbari Chermahini \& Hommel, 2011) can play decisive roles. Nevertheless, it seems clear that some sort of link exists between positive and negative mood on the one hand and creative thought processes on the other.

One idea regarding how mood and creative processes might interact considers mood as the cause and changes in creativity as effect. For instance, Ashby, Isen, and Turken (1999) assumed that mood creates particular brain states that facilitate or interfere with particular processing operations that are required for creative thinking. More recently, however, authors have also considered the possibility of a more reciprocal relationship between affective and cognitive processes (Bar, 2009; Gray, 2004; Gross, 2002; Salovey, Mayer, \& Caruso, 2002), which would allow creative thought to affect mood. For instance, Bar (2009) suggested an interactive relation between mood and cognitive control: The broad associative activation that is thought to coming along with positive mood may help gaining a broader perspective, which again might make people happier. Indeed, Srinivasan and Hanif (2011) reported that attending to the global aspect of visual stimuli facilitates the processing of happy as compared to sad faces 
while attending to the local aspects facilitates the processing of sad faces. Applied to the interaction between mood and creative thinking, this suggests that particular mood states may not only facilitate or hinder particular types of thought processes but some types of thought processes might also facilitate or even induce particular mood states.

In the present study, we tested this possibility by presenting participants with creative-thinking tasks and assessing whether this would lead to systematic mood changes. As divergent and convergent thinking have been attributed to different types of cognitive processes (Guilford, 1967) and given that they seem to rely on different neurocognitive states (Akbari Chermahini \& Hommel, 2010), we tested the impact of divergent thinking (assessed by the Alternate Uses Task, AUT: Guilford, 1967) and convergent thinking (assessed by the Remote Associates Task, RAT: Mednick, 1962) on mood separately by means of a between-subjects design.

Divergent-thinking tasks require participants to generate as many target-related responses as possible, and the target constrains the selection of possible responses rather weakly. An example is Guilford's (1967) AUT, which requires participants to generate as many uses for a simple object, such as a pen, as they can think of. Even though divergent thinking can be considered as just one of a number of component processes underlying creative acts (Guilford, 1967; Nijstad, De Dreu, Rietzschel, \& Baas, 2010; Wallas, 1926), recent reviews have revealed that the connection between divergent thinking and affect and mood is particularly strong and positive (Baas et al., 2008; Davis, 2009). Hence, more positive affect and mood improve divergent thinking. According to the reciprocity hypothesis under test, this suggests that the divergent-thinking task can be expected to induce a more positive mood state.

In contrast to divergent thinking, convergent thinking requires focusing onto one possible response per item and thus calls for a strongly constrained search process. As an example, in Mednick's (1962) RAT participants are presented with three concepts per trial, such as "hair", "stretch" and "time", and they are to identify the one concept that fits with all three in terms of association, meaning, or abstraction, such as "long" in the example. As we have argued elsewhere (Hommel, 2011; Hommel, Akbari Chermahini, van den Wildenberg, \& Colzato, 2011), succeeding in this task is likely to require a task set that in some sense is opposite to that implied by divergent thinking. Indeed, recently we were able to demonstrate that mixing convergent and divergent thinking tasks with other laboratory tasks results in a double dissociation: while engaging in convergent thinking facilitates subsequent performance in tasks that require focusing on relevant and excluding irrelevant information, divergent thinking facilitates subsequent performance in tasks that require the distribution of processing resources (Hommel et al., 2011). If we assume that opposite control states are accompanied by opposite mood states (for reasons that we elaborate in the Discussion), the observation that divergent thinking is related to positive mood would imply that convergent thinking is associated with negative mood. Accordingly, the reciprocity hypothesis would suggest that the convergent-thinking task induces a more negative mood state.

A second factor we considered was whether participants were only expecting to carry out the thinking task or whether they actually carried it out. This manipulation was motivated by informal observations of ours that participants often show affective responses to the mere announcement of the tasks that we commonly use to assess creative thinking (the AUT and the RAT). A similar reaction can be observed when intelligence or mathematical tasks are being announced, irrespective of the eventual score of the participant. This suggests that such reactions are not reflecting the individual ability or performance on the task but some kind of stereotypical response that may or may not be related to particular task characteristics. To dissociate such stereotypical and/or expectation-driven mood changes from changes that result from the actual processes engaged by the task, we had two groups of participants carry out the divergent or convergent thinking task and two other groups just waiting to perform these tasks (for about the same duration) after having been instructed how to carry it out.

\section{Method}

Participants, design, and procedure

Eighty-four students from Leiden University volunteered in exchange for course credit or pay. Participants were informed that they were participating in a study on problem solving. They were randomly assigned to one of the four experimental groups (22 to each of the performance groups and 20 to each of the preparation groups). Participants underwent four tasks or measurements: an inventory assessing their general mood (PANAS), a mood inventory (MI1) assessing their current feeling state before working on (or preparing for) a creativity task (either AUT or RAT), and another version of the MI (MI2) to assess their current feeling state after working on (or having prepared for) the creativity task. The order of the two versions was balanced across the participants.

The members of the four experimental groups all worked through the PANAS, the MI1, and the final MI2, but they differed with respect to the creativity task (see Table 1). The first group (DT) worked on a divergent- 
Table 1 Sequence of events for the four experimental groups

\begin{tabular}{lllll}
\hline Group & Pre-test & & Preparation & Execution \\
\hline DT & PANAS & MI1 & AUT & AUT \\
pDT & PANAS & MI1 & AUT & MI2 \\
CT & PANAS & MI1 & RAT & RAT \\
pCT & PANAS & MI1 & RAT & MI2 \\
\hline
\end{tabular}

PANAS positive and negative affect schedule, MII mood inventory (1st), AUT alternate uses task, RAT remote association task, MI2 mood inventory (2nd)

thinking task (AUT), which calls for the broad association on a particular theme (object use). The second group (pDT) was instructed to prepare for working on the same task, but the task was never actually performed. Analogously, the third group (CT) worked on a convergent-thinking task (RAT), which calls for finding one single correct response, whereas the fourth group ( $\mathrm{pCT}$ ) was instructed to prepare for working on the convergent-thinking task without performing it. To keep the timing comparable across the four groups, the members of groups pDT and pCT were to talk about the experiment and the instruction of either DT or CT with the experimenter for $5 \mathrm{~min}$ instead of performing the creativity task. The items of the creativity tasks were not presented to them.

Positive and negative affect schedule (PANAS)

The Positive and Negative Affect Schedule (PANAS; Watson, Clark, \& Tellegen, 1988) is a 20-item self-report mood scale that provides a general measure ("how do you feel generally?") of positive affect (PA) and negative affect (NA). The PANAS consists of ten positive adjectives (such as "interested", "alert", "excited") and ten negative adjectives (such as "disinterested", "upset", "guilty") rated on a Likert scale from 1 (very little or not at all) to 5 (very or extremely). Our Dutch version of the PANAS had high internal consistencies for both the PA (Cronbach's alpha $=0.84$ ) and the NA (Cronbach's alpha $=0.80$ ) subscale (cf., Hill, van Boxtel, Ponds, Houx \& Jolles, 2005).

\section{Mood inventory (MI)}

Two Dutch versions of the mood inventory employed by Phillips, Bull, Adams, and Fraser (2002) and Oaksford, Morris, Grainger, and Williams (1996), and similar to the scale of Isen, Daubman, and Nowicki (1987), were used to assess the current mood before and after preparing for and (in groups DT and CT) performing the creativity task. The items of this inventory assess three types of mood indicators (three hedonic, one physical arousal, and one worry measure; Phillips et al., 2002). One version (Cronbach's alpha $=0.75$ ) used the following adjective pairs (Dutch words are given in parentheses): happy-sad (blij-verdrietig), active-exhausted (actief-uitgeput), peaceful-anxious (verdig-angstig), carefree-serious (zorgeloos-serieus), and energetic-somber (energiek-sloom). The second version (Cronbach's alpha $=0.85$ ) used the pairs: positive-negative (positief-negatief), lively-tired (levendig-vermoeid), calm-uptight (kalm-opgewonden), bright-dispirited (helder-serieus), and cheerful-low (vrolijk-sloom). Positive and negative words were presented on the left and right side of a page, respectively. Nine-point Likert scales separated the words of each pair. Participants were asked to rate their current mood state (following Phillips et al., 2002). For further analyses, the mood scores were reversed for five items and then totaled for hedonic valence (items 1 , 3 , and 4), so that higher scores indicated more positive mood. Physical arousal (item 2), and worry (item 5) were scored separately.

\section{Alternate uses task (divergent thinking)}

In this task (based on Guilford, 1967, and translated into Dutch), participants were asked to list as many possible uses for a common household item (cup) as they can within 5 min. Responses can be scored with respect to four aspects (flexibility, originality, fluency, and elaboration), but given that flexibility seems to be by far the most reliable aspect (Akbari Chermahini \& Hommel, 2010; Ashby, Valentin, \& Turken, 2002), we considered only flexibility scores, which were derived from the number of different categories being used by the participant.

Remote association task (convergent thinking)

Mednick's Remote Associates Test (Mednick, Mednick, \& Mednick, 1964) (considered as a convergent thinking test) was originally designed in accord with Mednick's (1962) associative theory of creativity. Based on this theory, the creative thinking process consists in the formation of associative elements into new combinations which either meet specified requirements or are in some way useful. The original test consists of 30 items (Mednick, 1968; Mednick \& Mednick, 1967). Each item consists of three words that can be associated in one of several ways (e.g., time, hair, 
and stretch), such as forming a compound word or identifying a semantic associate (long). The items are constructed in such a way that only one solution is possible and that the first solution that comes to mind is commonly incorrect, which is why the test is taken to assess "remote" associations. Our Dutch version of the test comprised 30 items and was found to be reasonably reliable (Cronbach's alpha $=0.85$ ). In our study, participants were given $5 \mathrm{~min}$ to complete the test.

\section{Results}

Task performance

Performance in the AUT (flexibility score: $M=5.5$, $\mathrm{SD}=2.24)$ and the RAT $(\mathrm{M}=7.09, \mathrm{SD}=3.25)$ was good and comparable to performance in other studies using these task versions (e.g., Akbari Chermahini \& Hommel, 2010).

\section{General mood}

Table 2 provides an overview of the general mood states in the four experimental groups, as measured by the PANAS inventory. Two one-way ANOVAs with group as betweensubjects factor did not reveal any hint to pre-experimental differences between the four groups with respect to either the positive or the negative subscale of PANAS. The groups were thus comparable.

\section{Task-induced mood changes}

Mood changes were analyzed by means of three sets of three-way ANOVAs on the MI1 and MI2, using the hedonic valence score, the physical arousal score, and the worry score as dependent variables. Creativity task

Table 2 Mean and standard deviations for pre-experimental general mood states (positive and negative scales) in the four experimental groups

\begin{tabular}{lllll}
\hline State mood index & Groups & & \\
\cline { 2 - 5 } & $\begin{array}{l}\mathrm{DT} \\
(n=22)\end{array}$ & $\begin{array}{l}\mathrm{pDT} \\
(n=20)\end{array}$ & $\begin{array}{l}\mathrm{CT} \\
(n=22)\end{array}$ & $\begin{array}{l}\mathrm{pCT} \\
(n=20)\end{array}$ \\
\hline PANAS-P & & & & \\
M & 3.4 & 3.4 & 3.5 & 3.5 \\
SD & 0.3 & 0.5 & 0.5 & 0.5 \\
PANAS-N & & & & \\
M & 1.5 & 1.6 & 1.8 & 1.7 \\
SD & 0.5 & 0.5 & 0.5 & 0.6 \\
\hline
\end{tabular}

PANAS-P PANAS positive affect subscale, PANAS-N PANAS negative affect subscale (divergent thinking vs. convergent thinking) and activity (performing and preparing) served as between-subjects factors and timepoint (before vs. after the preparation or performance of the creativity task: MI1 vs. MI2) as withinsubjects factor. The alpha level was 0.05 .

Our actual hypotheses were tested by means of the hedonic valence ANOVA. There were only two reliable effects: an interaction between creativity task and timepoint, $F(1,80)=17.95, p<0.001, \eta^{2}=0.18$, that was modified by a three-way interaction with activity, $F(1,80)=4.06, p<0.05, \eta^{2}=0.05$. Separate ANOVAs showed that the task-by-timepoint interaction was reliable with performance, $F(1,42)=17.76, p<0.01, \eta^{2}=0.30$, and but not with preparation, $F(1,38)=2.85, p>0.05$, $\eta^{2}=0.07$. As shown in Fig. 1a, performing and, to a lesser degree, preparing for the DT task induced a more positive mood whereas performing and, to a lesser degree, preparing for the CT task induced a more negative mood. Interestingly, this pattern did not change when the individual

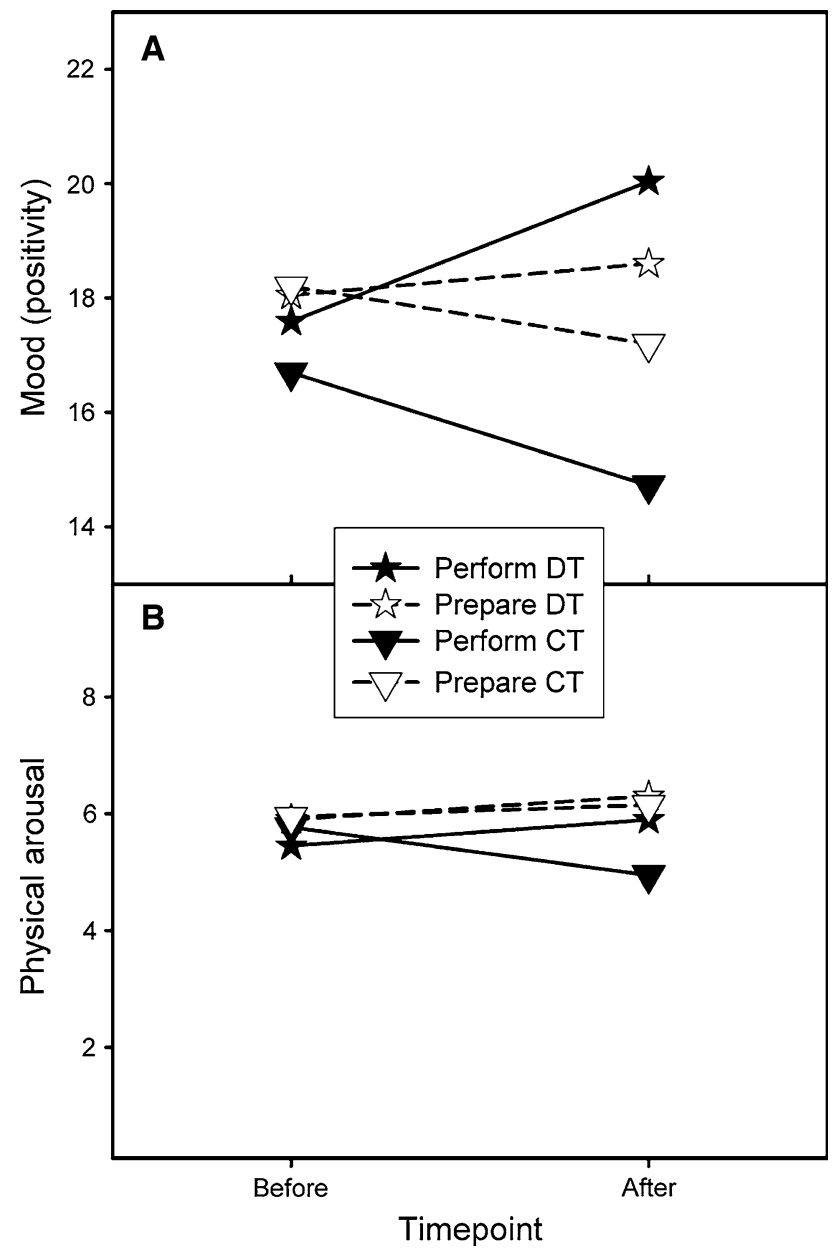

Fig. 1 Mood (a) and subjective physical arousal (b) as a function of creativity task (divergent thinking $=D T$, convergent thinking $=C T$ ), activity (performing and preparing the creativity task), and timepoint (before vs. after preparation or performance of the creativity task) 
performance in the creativity tasks was entered into the equation (as covariate) in the analyses of the performance groups (DT and CT), which rules out an account in terms of task difficulty and/or stress.

The analysis of the physical arousal score revealed only one reliable effect: an interaction between creativity task and timepoint, $F(1,80)=6.11, p<0.05, \eta^{2}=0.07$, even though the three-way interaction with activity approached significance, $F(1,80)=3.24, p=0.07, \eta^{2}=0.04$. Separate ANOVAs showed that the task-by-timepoint interaction was reliable with performance, $F(1,42)=7.43$, $p<0.01, \eta^{2}=0.15$, but not with preparation, $F(1,38)<1$. As shown in Fig. 1b, the outcome showed the same pattern as the hedonic valence data. The analysis of the worry score did not show any reliable effect, $F \mathrm{~s}<1$.

\section{Discussion}

The results are clear-cut. Most importantly, carrying out a task that requires creative thinking affects people's mood. This provides considerable support for the idea that mood and cognition are not only related, but also that this relation is fully reciprocal (Bar, 2009; Gray, 2004; Gross, 2002; Salovey et al., 2002). Moreover, divergent and convergent thinking impact mood in opposite ways: divergent thinking is improving one's mood while convergent thinking is lowering it. This dissociation is consistent with Akbari Chermahini and Hommel's (2010) observation that both types of thinking are related to one's dopamine level-the common currency that apparently mediates the interaction-but that these two relationships follow rather different functions. It also fits with the observation of Hommel et al. (2011) that convergent and divergent thinking support two different types of cognitive control. Finally, mood changes were particularly pronounced with actual task performance but mere preparation was also effective to some degree. The latter observation might suggest that divergent thinking and convergent thinking tasks evoke different, apparently even opposite stereotypical reactions which, as in intelligence tasks, do not seem to reflect individual performance and, thus, objective task characteristics. However, this effect might also indicate that preparing for divergent versus convergent thinking foreshadows the stronger performance-related effect, for instance because preparation involves the pre-activation of the very task-specific sets or states that are responsible for the mood swings that we observed. In any case, however, actually carrying out the task and, thus, the related thinking operations further boosts the task-specific mood changes to a degree that goes beyond possible stereotypical responses.

From a broader perspective, the outcome pattern of our study might be interpreted in three different ways.
According to the first, the divergent-thinking task is just "more fun". However, even though this account seems particularly intuitive (and is shared by many colleagues to whom we reported our findings), closer consideration reveals that its logical structure and actual meaning is less clear. To render this "fun" explanation more than a theoretically meaningless re-description of the findings, it would be necessary to identify some sort of factor that is responsible for the resulting fun or perceived pleasantness. The task's physical or structural characteristics are unlikely candidates, as it would be difficult to argue that being presented with three target stimuli and/or producing one response per trial is depressing while encountering one stimulus and/or producing a number of responses per trial is pleasant (especially if one considers that participants in the two preparation groups produced even more output in the filler task). More plausible would be a factor that also considers how participants deal with the characteristics of the tasks. On the one hand, these might be motivational factors reflecting the type and degree of challenge the different tasks are posing, and the motivational state this challenge creates. On the other hand, it might be more cognitive factors that reflect the kind of task sets the different tasks require. We will discuss these two possibilities in turn.

According to a motivational account, the different emotional consequences of the two tasks might reflect the differences in their demand characteristics. For instance, one may consider that the convergent-thinking task is more difficult than the divergent-thinking task (e.g., because it constrains responses more and/or because it takes longer to find a correct solution) and assume that easier tasks induce more positive, and more difficult tasks more negative mood. Even though this interpretation may seem intuitively plausible, closer consideration reveals that it runs into a number of theoretical and empirical problems. For one, people are known to be more motivated by tasks that are difficult but solvable than by easy tasks (for an overview, see Weiner, 1980). If we assume that combining high motivation and success is associated with positive mood, this suggests that, if anything, participants should show more positive mood after performing the convergentthinking task. A similar prediction could be made based on reward-related brain processes. It is known that rewardinduced brain responses are more pronounced the more unexpected success in a task is (Schultz, 1998). Given that reward is commonly assumed to lead to positive affect, this would suggest that identifying a correct response in a more difficult task is more rewarding and, thus, induces more positive mood than doing so in an easier task. Moreover, it makes sense to assume that the subjective difficulty is negatively correlated to the individual success. If so, participants who are performing more poorly in the 
convergent-thinking task should exhibit more negativegoing mood than better-performing participants. However, we have seen that entering individual performance into the analysis did not explain the task-by-timepoint interaction, which does not seem to support an account in terms of subjective difficulty.

This motivational interpretation considers the observed changes in mood mere byproducts of task difficulty or related task characteristics without a particular functional role or meaning. However, it is also possible that the mood changes reflect the way that the cognitive system is optimizing itself for the task at hand. The concept of mood refers to the personal level of analysis and implies a person having or being in the particular mood. At a systems level of analysis, this "being in a particular mood" implies the existence of a specific functional or neural state that corresponds to, and is correlated with this phenomenal experience. Probably the most systematic correlate of mood changes are changes in the individual dopamine level (Ashby et al., 1999), even though other neurotransmitter systems are also likely to be involved. Indeed, there is evidence from animal and human studies suggesting that the processing of positive and negative events is correlated with increases and decreases of the current dopamine level, respectively (Akbari Chermahini \& Hommel, 2011; Schultz, 1998). This implies that being in good or bad mood can be considered the experiential reflection of a brain state that, among other things, comprises an elevated or reduced dopamine level, respectively-mood and dopamine levels are thus two sides of the same coin. Interestingly, the current dopamine level is systematically related to performance in convergent- and divergentthinking tasks: while convergent thinking benefits from a low level, divergent thinking is best with a medium-to-high level (Akbari Chermahini \& Hommel, 2010). This implies that the optimal preparation for a convergent-thinking task would indeed consist in reducing the dopamine levelwhich would be accompanied by a more negative-going mood (Akbari Chermahini \& Hommel, 2011)—while the optimal preparation for a divergent-thinking task would consists in elevating the dopamine level-which would be accompanied by positive-going mood. In other words, the task-related mood changes we observed might be the experiential reflection of adaptive neuromodular changes that make sure that the cognitive system is optimally prepared for the task at hand.

We admit these are only speculations that call for further investigation. But they suggest the interesting possibility that people might be able to self-regulate their current dopamine level by adapting mood-related brain states to the cognitive requirements of the present task. From a more functional perspective, this would fit the idea that mood and cognitive control are more tightly related than commonly thought (Bar, 2009). Mood may thus not necessarily, or not only, be considered as a separable cause of particular control states, but, rather as the phenomenal expression of having such control states in place. In other words, different control states may feel differently. As our observations suggest, establishing and/or maintaining a focused, exclusive control state may come along with rather negative mood whereas a more distributed control state comes with rather positive mood.

If true, this has two interesting implications. Theoretically speaking, it would support approaches to human emotion that consider the phenomenal side effects of emotions-how an emotion makes one feel-less important than their functional implications-what an emotion does for our information processing. According to such approaches, different emotions go along with different types of readiness for particular types of actions (Frijda, 2007; James, 1884), such as fear and avoidance behavior (LeDoux, 1996). Our present findings suggest that this may not only hold for overt actions and action preparation but also for more general cognitive-control states. Practically speaking, the apparently close link between particular control states and particular mood states has the advantage of providing cues to assess the control state a given person is currently in. That is, someone's degree of positive or negative mood, and systematic changes therein, might provide important information about whether he or she is in a more focused or a more distributed control state. Given that mood states are commonly communicated through a broad range of perceivable cues, such as facial expression, body posture, or verbal style, this raises the exciting possibility that we might be able to directly perceive the control states of other people.

Acknowledgments The authors are grateful to Gernot Horstmann and Jan de Houwer for constructive comments on an earlier version of this article. The research of Soghra Akbari Chermahini is supported by a post-graduate scholarship $(\mathrm{PhD})$ of the Iranian Ministry of Science, Research and Technology. Address correspondence to Bernhard Hommel, Leiden University, Cognitive Psychology Unit, Wassenaarseweg 52, 2333 AK Leiden, The Netherlands; hommel@fsw.leidenuniv.nl.

Open Access This article is distributed under the terms of the Creative Commons Attribution Noncommercial License which permits any noncommercial use, distribution, and reproduction in any medium, provided the original author(s) and source are credited.

\section{References}

Akbari Chermahini, S., \& Hommel, B. (2010). The (b)link between creativity and dopamine: Spontaneous eye blink rates predict and dissociate divergent and convergent thinking. Cognition, 115, $458-465$. 
Akbari Chermahini, S., \& Hommel, B. (2011). More creative through positive mood? Not everyone! (Submitted).

Ashby, F. G., Isen, A. M., \& Turken, A. U. (1999). A neuropsychological theory of positive affect and its influence on cognition. Psychological Review, 106, 529-550.

Ashby, F. G., Valentin, V. V., \& Turken, A. U. (2002). The effects of positive affect and arousal on working memory and executive attention: neurobiology and computational models. In S. Moore \& M. Oaksford (Eds.), Emotional cognition: from brain to behaviour. Amsterdam: John Benjamins.

Baas, M., De Dreu, C. K. W., \& Nijstad, B. A. (2008). A metaanalysis of 25 years of research on mood and creativity: hedonic tone, activation, or regulatory focus? Psychological Bulletin, 134, 779-806.

Bar, M. (2009). A cognitive neuroscience hypothesis of mood and depression. Trends in Cognitive Sciences, 13, 456-463.

Bäuml, K.-H., \& Kuhbandner, C. (2009). Positive moods can eliminate intentional forgetting. Psychological Bulletin and Review, 16, 93-98.

Davis, M. A. (2009). Understanding the relationship between mood and creativity: a meta-analysis. Organizational Behavior and Human Decision Processes, 108, 25-38.

Frijda, N. H. (2007). The laws of emotion. Mahwah: Lawrence Erlbaum Associates.

Gasper, K., \& Clore, G. L. (2002). Attending to the big picture: mood and global vs. local processing of visual information. Psychological Science, 13, 34-40.

Gray, J. R. (2004). Integration of emotion and cognitive control. Current Directions in Psychological Science, 13, 46-48.

Gross, J. J. (2002). Emotion regulation: affective, cognitive, and social consequences. Psychophysiology, 39, 281-291.

Guilford, J. P. (1967). The nature of human intelligence. New York: McGraw-Hill.

Hanze, M., \& Hesse, F. (1993). Emotional influences on semantic priming. Cognition and Emotion, 7, 195-205.

Hill, R. D., van Boxtel, M. P. J., Ponds, R., Houx, P. J., \& Jolles, J. (2005). Positive affect and its relationship to free recall memory performance in a sample of older Dutch adults from the Maastricht Aging Study. International Journal of Geriatric Psychiatry, 20, 1-7.

Hirt, E. R., Melton, R. J., McDonald, H. E., \& Harackiewicz, J. M. (1996). Processing goals, task interest, and the mood-performance relationship: a mediational analysis. Journal of Personality and Social Psychology, 71, 245-261.

Hommel, B. (2011). Convergent and divergent operations in cognitive search. In: P.M. Todd, T.T. Hills, \& T.W. Robbins (Eds.), Cognitive search: Evolution, algorithms, and the brain. Strüngmann Forum Reports (Vol. 9). Cambridge: MIT Press (in press).

Hommel, B., Akbari Chermahini, S., van den Wildenberg, W.P.M., \& Colzato, L.S. (2011). Cognitive control of convergent and divergent thinking: a control-state approach to human creativity (Submitted).

Isen, A. M. (1999). On the relationship between affect and creative problem solving. In S. Russ (Ed.), Affect, creative experience, and psychological adjustment (pp. 3-17). London: Taylor \& Francis.
Isen, A. M., Daubman, K. A., \& Nowicki, G. P. (1987). Positive affect facilitates creative problem solving. Journal of Personality and Social Psychology, 52, 1122-1131.

James, W. (1884). What is an emotion? Mind, 9, 188-205.

LeDoux, J. E. (1996). The emotional brain. New York: Simon \& Schuster.

MacLeod, M. D. (2002). Retrieval-induced forgetting in eyewitness memory: forgetting as a consequence of remembering. Applied Cognitive Psychology, 16, 135-149.

Mednick, S. A. (1962). The associative basis of creative problem solving process. Psychological Review, 69, 200-232.

Mednick, S. A. (1968). Remote associates test. Journal of Creative Behavior, 2, 213-214.

Mednick, S. A., \& Mednick, M. P. (1967). Examiner's manual: Remote associates test. Boston: Houghton Mifflin.

Mednick, M. T., Mednick, S. A., \& Mednick, E. V. (1964). Incubation of creative performance and specific associative priming. Journal of Abnormal and Social Psychology, 69, 84-88.

Nijstad, B. A., De Dreu, C. K. W., Rietzschel, E. F., \& Baas, M. (2010). The dual pathway to creativity model: Creative ideation as a function of flexibility and persistence. European Review of Social Psychology, 21, 34-77.

Oaksford, M., Morris, F., Grainger, B., \& Williams, J. M. G. (1996). Mood, easoning, and central executive processes. Journal of Experimental Psychology. Learning, Memory, and Cognition, 22, 477-493.

Pham, M. T. (2007). Emotion and rationality: a critical review and interpretation of empirical evidence. Review of General Psychology, 11, 155-178.

Phillips, L. H., Bull, R., Adams, E., \& Fraser, L. (2002). Positive mood and executive function: evidence from stroop and fluency tasks. Emotion, 2, 12-22.

Rowe, G., Hirsh, J. B., \& Anderson, A. J. (2007). Positive affect increases the breadth of attentional selection. Proceedings of the National Academy of Sciences of the United States of America, 104, 383-388.

Salovey, P., Mayer, J. D., \& Caruso, D. (2002). The positive psychology of emotional intelligence. In C. R. Snyder \& S. J. Lopez (Eds.), The handbook of positive psychology (pp. 159-171). New York: Oxford University Press.

Schultz, W. (1998). Predictive reward signal of dopamine neurons. Journal of Neurophysiology, 80, 1-27.

Srinivasan, N., \& Hanif, A. (2011). Global-happy and local-sad: Perceptual processing affects emotion identification. Cognition \& Emotion (in press).

Teasdale, J. D., \& Fogarty, S. J. (1979). Differential effects of induced mood on retrieval of pleasant and unpleasant events from episodic memory. Journal of Abnormal Psychology, 88, $248-257$.

Wallas, G. (1926). The art of thought. New York: Harcourt Brace.

Watson, D., Clark, L. A., \& Tellegen, A. (1988). Development and validation of brief measures of positive and negative affect: the PANAS Scales. Journal of Personality and Social Psychology, 54, 1063-1070.

Weiner, B. (1980). Human motivation. New York Holt: Rinehart \& Winston. 